\title{
Patterns and Changes in the Treatment of Patients with Type II Diabetes Mellitus in Egypt: The DISCOVER Program
}

\author{
Salah Shelbaya ${ }^{*}$, Mohamed Khattab ${ }^{2}$, Khalifa Abdallah ${ }^{3}$, Yehia Ghanem ${ }^{3}$, Hesham El Hefnawy ${ }^{4}$, \\ Enas Shaltout ${ }^{5}$, Eman Roshdy², Emad R. Issak ${ }^{6}$
}

${ }^{1}$ Endocrinology Department, Ain Shams University, Cairo, Egypt

${ }^{2}$ Internal Medicine Department, Cairo University, Giza, Egypt

${ }^{3}$ Internal Medicine Department, Alexandria University, Alexandria, Egypt

${ }^{4}$ Endocrinology Department, National Institute of Diabetes \& Endocrinology, Cairo, Egypt

${ }^{5}$ Internal Medicine Department, Diabetes Unit, Cairo University, Giza, Egypt

${ }^{6}$ Internal Medicine Department, Ain Shams University, Cairo, Egypt

Email: *Salahshelbaya@hotmail.com

How to cite this paper: Shelbaya, S., Khattab, M., Abdallah, K., Ghanem, Y., El Hefnawy, H., Shaltout, E., Roshdy, E. and Issak, E.R. (2020) Patterns and Changes in the Treatment of Patients with Type II Diabetes Mellitus in Egypt: The DISCOVER Program. International Journal of Clinical Medicine, 11, 731-742.

https://doi.org/10.4236/ijcm.2020.1112054

Received: October 29, 2020

Accepted: November 28, 2020

Published: December 1, 2020

Copyright $\odot 2020$ by author(s) and Scientific Research Publishing Inc. This work is licensed under the Creative Commons Attribution International License (CC BY 4.0).

http://creativecommons.org/licenses/by/4.0/

\begin{abstract}
The DISCOVER study is a three-year, non-interventional prospective study conducted in 37 countries, including Egypt, to assess the treatment patterns and outcomes in patients with type 2 diabetes mellitus initiating a second-line antidiabetic therapy (add-on or switch). In this report of the Egyptian cohort of DISCOVER, baseline data were collected according to routine clinical practice at 38 study sites, using a standardized electronic case report form, in the period from December-2014 to November-2019. We enrolled 583 patients (mean age: $52.9 \pm 9.8$ years and median duration since diagnosis: median 36.5, IQR 18.1, 70.4 months). The mean HbAlc value at baseline was $8.6 \pm 1.4 \%$, indicating poor glycemic control. The most commonly prescribed first-line medications were metformin or sulfonylurea monotherapy. For second linetherapy, the majority of patients switched to dual therapy with metformin plus sulfonylureas or DPP-4 inhibitors. Fewer patients switched to triple therapy, treatment by four or more medications, or insulin treatment $(15,12$, and 35 patients, respectively). The most commonly cited reasons for switching to second-line therapy were lack of efficacy, weight gain, hypoglycemic events, and side effects $(549,54,25$, and 21 patients, respectively). The set treatment target of enrolled patients at the initiation of second-line therapy was an $\mathrm{HbAlc}$ level of $6.9 \%$. Follow-up data will assess the outcomes of such changes in the Egyptian population.
\end{abstract}




\section{Keywords}

Diabetes Mellitus, Glucose Control, Metformin, Patient-Reported Outcomes, Egypt, HbA1c, Medication

\section{Introduction}

Approximately 420 million individuals worldwide have type 2 diabetes mellitus (T2DM). This prevalence is expected to reach 642 million individuals by 2040 [1] [2]. The International Diabetes Federation (IDF) classifies Egypt as the ninth leading country in terms of T2DM prevalence (around 15\% of the adult Egyptian population), with an estimated annual mortality of 86,478 [3] [4]. Additionally, as many as $40 \%$ of T2DM patients in Egypt remain undiagnosed [3]. Due to its macrovascular and microvascular complications, T2DM remains the leading cause of retinopathy and vision loss, peripheral neuropathy, chronic nephropathy, and leg amputation in Egypt [5] [6].

Recent guidelines from the American Diabetes Association (ADA) and the American College of Endocrinology recommend tight glucose control ( $\mathrm{HbA1c}<7 \%$ ) for newly-diagnosed patients with T2DM and those with long life expectancy [7] [8]. These guidelines are based on the results of long-term studies that showed reduced mortality and reductions in cardiovascular and microvascular complications when glucose levels are tightly controlled [9] [10]. Both ADA and The European Association for the Study of Diabetes (EASD) recommend metformin (MET) added to lifestyle modifications as the first-line glucose-lowering therapy in patients with T2DM. If MET monotherapy fails to adequately control HbA1c levels, guidelines recommend adding a second glucose-lowering agent, but few clearly state optimal treatment pathways [7] [8].

Understanding the real-life patterns and outcomes of T2DM treatment is essential to aid in developing new strategies aimed at optimal blood glucose control. For example, previous studies have shown sub-optimal adherence to glucose-lowering treatment as a barrier to achieving glycemic target among Egyptian diabetic patients. They also concluded that the number of prescribed medications, the therapeutic regimen's complexity, and the treatment costs negatively affect the adherence rates [11] [12].

We have no recent studies about the treatment patterns and outcomes in patients with T2DM in Egypt to the best of our knowledge. The DISCOVER study is a three-year, non-interventional, prospective study, conducted in 37 countries, including Egypt (NCT02322762), to assess the pharmacological patterns (firstand second-line therapy) and outcomes (level of glycemic control) in patients with T2DM who are initiating second-line glucose-lowering therapy. Here we report the baseline characteristics (including HbAlc values) of the enrolled Egyptian patients and the reasons for changing their first-line antidiabetic treatments. 


\section{Methods}

\subsection{Study Design and Population}

The DISCOVER study is a prospective, multi-national study performed in 37 countries, including Egypt. We enrolled an average of 15 patients per center from 38 centers (including 36 primary health care centers). These centers had specialty care, electronic medical records, and an adequate flow of T2DM patients ( $>50$ patients/month). The predominant mode of referral to these centers was from primary care clinics. In Egypt, the study was conducted in the period of December-2014 to November-2019.

\subsection{Inclusion and Exclusion Criteria}

In this study, patients were enrolled if they were aged $>18$ years, diagnosed with T2DM, and were initiating a second-line antidiabetic treatment (add-on or switch). We excluded patients with T1DM, pregnant women, patients with a renal transplant or undergoing dialysis, and patients whose first-line treatment was either insulin (or another injectable agent) or herbal remedies and natural medicines alone.

\subsection{Study Variables}

Baseline data were collected according to routine clinical practice at each site, using a standardized electronic case report form. Baseline variables recorded included: demographic and physiological parameters, treatment options and reasons for treatment change, individualized HbAlc targets set by physicians, and laboratory test results, including $\mathrm{HbA1c}$ level, when available. We assessed the health status of enrolled patients using the Short-Form 36 (SF-36) version 2 questionnaire. The main endpoints in this report are the level of glycemic control $(\mathrm{HbAlc})$ at baseline, the proportions of patients using different antidiabetic regimens and medications, and the reasons for changing to second-line treatments.

\subsection{Sample Size Calculation and Statistical Analysis}

The multinational DISCOVER study in 37 countries, including Egypt, has an estimated overall sample size of 11,100 patients based on the four criteria mentioned in Ji L et al. (2017). These criteria are a minimum of 200 patients in any subgroup of patients, at least 200 patients meeting each of the composite endpoints of macrovascular and microvascular complications, at least 200 patients meeting each macrovascular and microvascular endpoint at year 3 , and an estimated attrition rate of $15 \%$ per year of follow-up [13].

Categorical data were presented as frequencies and percentages, while continuous data were presented as means \pm standard deviations, as well as medians and interquartile ranges (IQR). All presented statistical analyses were carried out using SAS (version 9.2; SAS Institute Inc., Cary, NC, USA). For some outcomes, data were not available from all patients; therefore, patients with missing data 
were excluded from the analysis.

\section{Results}

\subsection{Baseline Patient Characteristics}

The mean age of the enrolled 583 patients was $52.9 \pm 9.8$ years. The majority of patients in our sample were male (56.6\%). The mean BMI was $31.8 \pm 5.1 \mathrm{~kg} / \mathrm{m}^{2}$, and 115 patients were current smokers or ex-smokers (91 and 24 patients, respectively). At baseline, the mean values of blood glucose measures indicated poor glycemic control: HbAlc $(8.6 \% \pm 1.4 \%)$, fasting plasma glucose $(182.8 \pm$ $53.7 \mathrm{mg} / \mathrm{dL})$, and post-prandial blood glucose $(257.3 \pm 70.4 \mathrm{mg} / \mathrm{dL})$. About $36 \%$ of patients had hypertension, and $25.9 \%$ had hyperlipidemia. However, the mean values of lipid profile components (total cholesterol, triglycerides, LDL, and HDL) were within or near the normal ranges (Table 1).

Table 1. (a) Baseline demographic characteristics, vital signs and lab values in enrolled patients; (b) Vital signs and lab values in enrolled patients.

(a)

\begin{tabular}{|c|c|}
\hline & Total $(\mathrm{N}=583)$ \\
\hline \multicolumn{2}{|l|}{ Age (years) } \\
\hline Mean \pm SD & $52.9 \pm 9.8$ \\
\hline Median (IQR) & $53.0(46.1,59.1)$ \\
\hline \multicolumn{2}{|l|}{ Gender } \\
\hline Male & $330(56.6)$ \\
\hline Female & $253(43.4)$ \\
\hline \multicolumn{2}{|l|}{ BMI $\left(\mathrm{kg} / \mathrm{m}^{2}\right)$} \\
\hline Mean \pm SD & $31.8 \pm 5.1(527)$ \\
\hline Median (IQR) & $31.1(28.1,34.6)$ \\
\hline \multicolumn{2}{|l|}{ Waist circumference $(\mathrm{cm})$} \\
\hline Mean \pm SD & $104.5 \pm 24.3(337)$ \\
\hline Median (IQR) & $105(96,120)$ \\
\hline \multicolumn{2}{|l|}{ Self-reported ethnicity } \\
\hline Caucasian & $35(6)$ \\
\hline Arabic & $548(94)$ \\
\hline \multicolumn{2}{|l|}{ Living arrangement status } \\
\hline Lives alone & $14 / 564(2.5)$ \\
\hline Does not live alone & $548 / 564(97.2)$ \\
\hline Declined to answer & $2 / 564(0.4)$ \\
\hline \multicolumn{2}{|l|}{ Education level } \\
\hline No formal education & $19 / 558(3.4)$ \\
\hline Primary ( 1 - 6 years of education) & $63 / 558(11.3)$ \\
\hline
\end{tabular}




\section{Continued}

\begin{tabular}{lc}
\hline Secondary (7 - 13 years of education) & $172 / 558(30.8)$ \\
University/Higher Education (13+ years) & $304 / 558(54.5)$ \\
Main working status & $319 / 572(55.8)$ \\
Employed & $46 / 572(8)$ \\
Self-Employed & $1 / 572(0.2)$ \\
Disabled & $162 / 572(28.3)$ \\
Not working & $44 / 572(7.7)$ \\
Retired & \\
Tobacco Smoking & $458 / 573(79.9)$ \\
Non-smoker & $24 / 573(4.2)$ \\
Ex-smoker & $91 / 573(15.9)$ \\
Current smoker & \\
\hline
\end{tabular}

Data are number (\%) for categorical outcomes or mean \pm standard deviation and median (IQR) for continuous outcomes. BMI: Body mass index.

(b)

\begin{tabular}{|c|c|}
\hline & Total $(\mathrm{N}=583)$ \\
\hline \multicolumn{2}{|l|}{ Systolic BP (mm. Hg) } \\
\hline Mean \pm SD & $133.0 \pm 14.9(555)$ \\
\hline Median (IQR) & $130(120,140)$ \\
\hline \multicolumn{2}{|l|}{ Diastolic BP (mm. Hg) } \\
\hline Mean \pm SD & $82.8 \pm 8.6(555)$ \\
\hline Median (IQR) & $80(80,90)$ \\
\hline \multicolumn{2}{|l|}{ Pulse rate at rest (bpm) } \\
\hline Mean \pm SD & $78.4 \pm 6.8(583)$ \\
\hline Median (IQR) & $80(74,82)$ \\
\hline \multicolumn{2}{|l|}{ HbA1C (\%) } \\
\hline Mean \pm SD & $8.6 \pm 1.4(543)$ \\
\hline Median (IQR) & $8.4(7.9,9.1)$ \\
\hline \multicolumn{2}{|l|}{ Fasting Glucose (mg/dL) } \\
\hline Mean \pm SD & $182.8 \pm 53.7(543)$ \\
\hline Median (IQR) & $177(149,208)$ \\
\hline \multicolumn{2}{|l|}{ Random Glucose (mg/dL) } \\
\hline Mean \pm SD & $250.6 \pm 59.9(113)$ \\
\hline Median (IQR) & $250(206,297)$ \\
\hline \multicolumn{2}{|c|}{ Post Prandial Glucose (mg/dL) } \\
\hline Mean \pm SD & $257.3 \pm 70.4(501)$ \\
\hline Median (IQR) & $249(213,295)$ \\
\hline \multicolumn{2}{|l|}{$\mathrm{HDL}(\mathrm{mg} / \mathrm{dL})$} \\
\hline Mean \pm SD & $43.6 \pm 9.6(218)$ \\
\hline
\end{tabular}




\section{Continued}

\begin{tabular}{cc}
\hline Median (IQR) & $42(38,49)$ \\
LDL $(\mathrm{mg} / \mathrm{dL})$ & $124.3 \pm 37.9(227)$ \\
Mean $\pm \mathrm{SD}$ & $125(95,154)$ \\
Median (IQR) & \\
Total Cholesterol (mg/dL) & $201.6 \pm 45.1(264)$ \\
Mean \pm SD & $200(170,230.5)$ \\
Median (IQR) & $164.5 \pm 81.6(258)$ \\
Triglycerides (mg/dL) & $150(112,189)$ \\
Mean \pm SD & \\
Median (IQR)
\end{tabular}

Data are mean \pm standard deviation and median (IQR) for continuous outcomes for continuous outcomes. BP: blood pressure, HDL: High-density lipoprotein, LDL: Low-density lipoprotein.

At the start of this study, the duration of T2DM since diagnosis was $49.2 \pm$ 44.3 (median 36.5, IQR: 18.1, 70.4) months. The majority $(\mathrm{n}=508,87.1 \%)$ have the diagnose of T2DM following the appearance of diabetes-related symptoms, while only $61(10.5 \%)$ and $14(2.4 \%)$ have that diagnosis upon routine monitoring or referral, respectively. The most common macrovascular complication was coronary artery disease (7.5\%), while the most common microvascular complications were peripheral neuropathy (14.8\%) and erectile dysfunction (5\%). The most commonly used medications for other conditions were antihypertensive (38.8\%), lipid-lowering medications (33.8\%), and antiplatelet medications (17.5\%). Our results showed impairments in all measured health status domains (average below 50), according to SF-36v2.

\subsection{First-Line Antidiabetic Treatments}

At the baseline, the majority of patients 435 (74.6\%) were on monotherapy, predominantly receiving metformin (234 patients) or sulfonylurea (193 patients). Only 137 patients (23.5\%) were receiving dual therapy, mainly in the form of metformin plus sulfonylureas or DPP-4 inhibitors. Overall, ten patients received triple therapy. Nine of them received triple therapy containing metformin and sulfonylureas plus DPP-4 inhibitors or thiazolidinediones in our sample, as shown in Table 2.

\subsection{Second-Line Antidiabetic Treatments}

The mean time from diagnosis to the initiation of second-line therapy was 5.6 years. The majority of patients $(\mathrm{n}=361,62 \%)$ were shifting to dual therapy, mainly in the form of metformin plus DPP-4 inhibitors (27.5\%) or sulfonylureas (25.6\%). One hundred twenty-one patients (20.7\%) initiated triple therapy, mainly in the form of metformin and Sulfonylureas plus DPP-4 inhibitors or thiazolidinediones. Only 12 and 35 patients switched to $\geq$ four drugs or insulin (with or without oral medications), respectively (Table 2). 
Table 2. First and second line treatment medications in the enrolled sample.

\begin{tabular}{lcc}
\hline & \multicolumn{2}{c}{ Total (N =582) } \\
\hline & First Line Class & Second Line Drugs \\
\hline Monotherapy & $234(40.2 \%)$ & $12(2.1 \%)$ \\
Met & $193(33.2 \%)$ & $11(1.9 \%)$ \\
SU & $4(0.7 \%)$ & $25(4.3 \%)$ \\
DPP4 & $4(0.7 \%)$ & $5(0.9 \%)$ \\
Other & & $149(25.6 \%)$ \\
Dual Therapy & $103(17.7 \%)$ & $160(27.5 \%)$ \\
Met + SU & $24(4.1 \%)$ & $10(1.7 \%)$ \\
Met + DPP4 & $3(0.5 \%)$ & $10(1.7 \%)$ \\
Met + other & & $32(5.5 \%)$ \\
SU + Thiaz & $7(1.2 \%)$ & $12(2.1 \%)$ \\
Other Dual therapy & & $35(6.0 \%)$ \\
\hline Triple Therapy & $6(1.0 \%)$ & $21(3.6 \%)$ \\
Met + SU + DPP4 & $3(0.5 \%)$ & $15(2.6 \%)$ \\
Met + SU + Thiaz & $1(0.2 \%)$ & \\
Other Triple therapy & &
\end{tabular}

\subsection{Reasons Underlying Treatment Changes}

The most common reason for changing first-line medications was lack of efficacy $(\mathrm{n}=549$ patients; $94.2 \%)$. Less common reasons included weight gain, the occurrence of hypoglycemic events, and side effects $(9.3 \%, 4.3 \%$, and $3.6 \%$, respectively). Second-line therapy was started to achieve higher efficacy, tolerability, and to avoid both weight gain and hypoglycemic events $(87.1 \%, 32.6 \%, 26.1 \%$, and $22.3 \%$, respectively). Seeking more affordable cost was mentioned as a reason for selecting second-line treatments in 48 patients (8.2\%) (Table 3). At the initiation of second-line treatment, a target HbAlc goal was set for 447 (76.7\%) patients. The mean target $\mathrm{HbAlc}$ was $6.9 \% \pm 0.4 \%$. Physicians reported few restrictions on prescribing the majority of available drugs to the study patients. However, physicians reported restrictions in prescribing alpha-glucosidase, acarbose, and rosiglitazone for 70 (12\%), 62 (10.6\%), and 43 (7.4\%) patients, respectively.

\section{Discussion}

The DISCOVER study program was established to improve understanding of the treatment patterns and outcomes of patients with T2DM at the global level. In this report of the DISCOVER baseline data from Egypt, we present the treatment patterns of patients with T2DM, for which data have been scarce on this so far. 
Table 3. Changing first-line therapy and switching to second-line therapy

\begin{tabular}{|c|c|}
\hline & Total $(\mathrm{N}=583)$ \\
\hline \multicolumn{2}{|l|}{ Consult Setting } \\
\hline Inpatient & $10 / 558(1.8 \%)$ \\
\hline Outpatient & $548 / 558(98.2 \%)$ \\
\hline Hospitalization for facilitating diabetes treatment change & $3 / 547(0.5 \%)$ \\
\hline \multicolumn{2}{|l|}{ Reason for changing First Line Therapy } \\
\hline Lack of Efficacy & $549(94.2 \%)$ \\
\hline Hypoglycemic Event & $25(4.3 \%)$ \\
\hline Weight Gain & $54(9.3 \%)$ \\
\hline Side Effect & $21(3.6 \%)$ \\
\hline Developed Acute Disease & $2(0.3 \%)$ \\
\hline Developed Chronic Disease & $2(0.3 \%)$ \\
\hline Affordability & $0(0.0 \%)$ \\
\hline Inability to Self-administer & $5(0.9 \%)$ \\
\hline Patient Request & $13(2.2 \%)$ \\
\hline Poor adherence & $17(2.9 \%)$ \\
\hline Patient convenience & $7(1.2 \%)$ \\
\hline Prescriber access reasons & $1(0.2 \%)$ \\
\hline Drug interaction & $0(0.0 \%)$ \\
\hline Physician preference & $9(1.5 \%)$ \\
\hline \multicolumn{2}{|l|}{ Reason for Choosing a Second-Line Therapy } \\
\hline Efficacy & $508(87.1 \%)$ \\
\hline Tolerability & $190(32.6 \%)$ \\
\hline Weight & $152(26.1 \%)$ \\
\hline Hypoglycemic & $130(22.3 \%)$ \\
\hline Patient request & $28(4.8 \%)$ \\
\hline Convenience & $37(6.3 \%)$ \\
\hline Access Reason & $4(0.7 \%)$ \\
\hline Cost & $48(8.2 \%)$ \\
\hline Other & $9(1.5 \%)$ \\
\hline
\end{tabular}

We noted several significant findings. At baseline, the mean $\mathrm{HbAlc}$ value was $8.6 \%$, which indicates poor glycemic control. High HbAlc levels are correlated with a higher incidence of vascular complications [14] [15]. The low percentage (9.8\%) of macrovascular complications in this study may not reflect the real picture; such underestimation may be due to the lack of resources for performing investigations like electrocardiogram (ECG) and echocardiography in Egypt. The mean target aim for $\mathrm{HbAlc}$ in enrolled patients at the initiation of second-line treatment was $6.9 \%$. That is in accordance with the recent guidelines that rec- 
ommended setting treatment goals for HbA1c below 7\% [7] [8]. These guidelines are based on the results of several studies that showed that keeping HbA1c below $7 \%$ significantly reduces the incidence of macrovascular and microvascular complications [9] [10].

The most common medication used as a first-line antidiabetic treatment in our study was metformin. This is in accordance with the current NICE and ADA guidelines [7] [16]. Moreover, the most common second-line therapy was dual therapy, mainly metformin plus SU or DPP-4 inhibitors. That reflects good adherence to international guidelines by Egyptian physicians treating patients with T2DM. In our exclusion criteria, we excluded patients whose first-line treatment included insulin or any other injectable agent. During treatment intensification, 35 patients $(6 \%)$ switched to insulin (with or without oral medications). A former observational study of 51,771 patients showed that physicians were reluctant to prescribe injectable agents [17].

The most common reason for changing first-line antidiabetic therapy was lack of efficacy, and the most common reason for transitioning to second-line therapy was seeking better glucose control. That agrees with previous studies that showed that high HbA1c levels were the main driver behind switching to second-line antidiabetic therapy [18] [19]. The occurrence of side effects or hypoglycemic attacks was a less common reason for treatment changes. A former study by Asche et al. (2008) showed that adverse events did not significantly affect glycemic control but increased the rates of switching drugs, especially for patients on metformin or sulfonylureas [20]. Our results showed that weight gain was a relatively common adverse event that led to shifting to second-line treatments in 54 (9.3\%) patients. Although previous studies have shown sub-optimal adherence among Egyptian DM patients [11] [12], in this study, it was not a common reason for shifting treatments (only cited in 17 cases).

Another interesting finding in our study was the small proportion of patients diagnosed with T2DM through regular blood glucose screening. That highlights the need for increasing the exerted efforts towards public education and awareness about the value of continuous blood glucose screening, especially in highrisk patients. Moreover, the prevalence of comorbidities like hypertension and hyperlipidemia (as indicated by the frequency of receiving concomitant medications for these conditions) was relatively high in the enrolled Egyptian patients. Therefore, multidisciplinary medical management and considering the presence of these comorbidities while prescribing antidiabetic medications is necessary.

Our study analyzed data from a relatively sizeable Egyptian population. Further, we attempted to evaluate the patient-reported outcomes, as well as the quality of life in Egyptian patients with T2DM. The study went further to determine the restrictions faced by physicians in prescribing various hypoglycemic medications. Our prospective analysis after collecting of follow-up data will focus on the outcomes of second-line treatments and provide further guidance for physicians on the optimal treatment options for Egyptian diabetic patients. More- 
over, it will present data on the factors associated with prescribing specific treatments and the variations in diabetology practice across different countries.

One advantage of this current study was that it had a relatively enough sample from different centers all over Egypt; hence, it represented the overall population of people with T2DM well. However, the study's main limitation was its observational nature with some variables that could be exposed to recall bias.

\section{Conclusion}

In conclusion, this study showed poor glycemic control among Egyptian patients with T2DM initiating second-line treatment. Therefore, the lack of efficacy was the most common reason for changing first-line treatments. Dual therapy in the form of metformin plus Sulfonylureas or DPP-4 inhibitors was the most commonly prescribed second-line treatment. Follow-up data will assess the outcomes of such changes in the Egyptian population.

\section{Compliance with Ethical Standards}

\section{Conflicts of Interest}

All first seven authors were or are members of the DISCOVER Scientific Committee.

In addition, all first seven authors have received honoraria and research grants from Boehringer Ingelheim, Bristol-Myers Squibb, Eli Lilly, Merck, Sharp \& Dohme, Novartis, Novo Nordisk, Janssen, and Sanofi.

\section{Funding Sources}

This study was funded by AstraZeneca.

\section{Ethical Approval}

ClinicalTrials.gov identifiers: NCT02322762 (DISCOVER) and NCT02226822 (J-DISCOVER).

\section{References}

[1] American Diabetes Association (2015) Diabetes Statistics. http://www.diabetes.org

[2] US Center of Disease Prevention and Control (2014) National Diabetes Statistics Report. http://www.cdc.gov/diabetes/data/statistics/2014statisticsreport.html

[3] Hegazi, R., El-Gamal, M., Abdel-Hady, N. and Hamdy, O. (2015) Epidemiology of and Risk Factors for Type 2 Diabetes in Egypt. Annals of Global Health, 81, 814-820. https://doi.org/10.1016/j.aogh.2015.12.011

[4] Whiting, D.R., Guariguata, L., Weil, C. and Shaw, J. (2011) IDF Diabetes Atlas: Global Estimates of the Prevalence of Diabetes for 2011 and 2030. Diabetes Research and Clinical Practice, 94, 311-321. https://doi.org/10.1016/j.diabres.2011.10.029

[5] Bos, M. and Agyemang, C. (2013) Prevalence and Complications of Diabetes Mellitus in Northern Africa, a Systematic Review. BMC Public Health, 13, Article No. 387. https://doi.org/10.1186/1471-2458-13-387 
[6] El Husseny, M.W.A., Mamdouh, M., Shaban, S., Ibrahim Abushouk, A., Zaki, M.M.M., Ahmed, O.M. and Abdel-Daim, M.M. (2017) Adipokines: Potential Therapeutic Targets for Vascular Dysfunction in Type II Diabetes Mellitus and Obesity. Journal of Diabetes Research, 2017, Article ID: 8095926. https://doi.org/10.1155/2017/8095926

[7] Marathe, P.H., Gao, H.X. and Close, K.L. (2017) American Diabetes Association Standards of Medical Care in Diabetes 2017. Journal of Diabetes, 9, 320-324. https://doi.org/10.1111/1753-0407.12524

[8] Handelsman, Y., Bloomgarden, Z.T., Grunberger, G., Umpierrez, G., Zimmerman, R.S., Bailey, T.S. and Blonde, L. (2015) American Association of Clinical Endocrinologists and American College of Endocrinology-Clinical Practice Guidelines for Developing a Diabetes Mellitus Comprehensive Care Plan-2015. Endocrine Practice, 21, 1-87. https://doi.org/10.4158/EP15672.GLSUPPL

[9] The ADVANCE Collaborative Group (2008) Intensive Blood Glucose Control and Vascular Outcomes in Patients with Type 2 Diabetes. New England Journal of Medicine, 358, 2560-2572. https://doi.org/10.1056/NEJMoa0802987

[10] Lazar, H.L., Chipkin, S.R., Fitzgerald, C.A., Bao, Y.S., Cabral, H. and Apstein, C.S. (2004) Tight Glycemic Control in Diabetic Coronary Artery Bypass Graft Patients Improves Perioperative Outcomes and Decreases Recurrent Ischemic Events. Circulation, 109, 1497-1502. https://doi.org/10.1161/01.CIR.0000121747.71054.79

[11] Shams, M.E. and Barakat, E.A. (2010) Measuring the Rate of Therapeutic Adherence among Outpatients with T2DM in Egypt. Saudi Pharmaceutical Journal, 18, 225-232. https://doi.org/10.1016/j.jsps.2010.07.004

[12] Koura, M.R., Khairy, A.E., Abdel-Aal, N.M., Mohamed, H.F., Amin, G.A. and Sabra, A.Y. (2001) The Role of Primary Health Care in Patient Education for Diabetes Control. The Journal of the Egyptian Public Health Association, 76, 241-264.

[13] Ji, L.N., Bonnet, F., Charbonnel, B., Gomes, M.B., Kosiborod, M., Khunti, K., et al. (2017) Towards an Improved Global Understanding of Treatment and Outcomes in People with Type 2 Diabetes: Rationale and Methods of the DISCOVER Observational Study Program. Journal of Diabetes and Its Complications, 31, 1188-1196. https://doi.org/10.1016/j.jdiacomp.2017.03.011

[14] Zoungas, S., Chalmers, J., Ninomiya, T., Li, Q., Cooper, M.E., Colagiuri, S., et al. (2012) Association of HbA1c Levels with Vascular Complications and Death in $\mathrm{Pa}$ tients with Type 2 Diabetes: Evidence of Glycaemic Thresholds. Diabetologia, 55, 636-643. https://doi.org/10.1007/s00125-011-2404-1

[15] O’sullivan, C., Hynes, N., Mahendran, B., Andrews, E.J., Avalos, G., Tawfik, S., Lowery, A., Sultan, S. (2006) Haemoglobin A1c (HbA1C) in Non-Diabetic and Diabetic Vascular Patients. Is HbA1C an Independent Risk Factor and Predictor of Adverse Outcome? European Journal of Vascular and Endovascular Surgery, 32, 188 197. https://doi.org/10.1016/j.ejvs.2006.01.011

[16] O’Hare, J.P., Miller-Jones, D., Hanif, W., Hicks, D., Evans, M., Leslie, D., Bain, S.C. and Barnett, A.H. (2015) The New NICE Guidelines for Type 2 Diabetes-A Critical Analysis. British Journal of Diabetes, 15, 3-7. https://doi.org/10.15277/bjdvd.2015.006

[17] Levin, P.A., Wei, W.H., Zhou, S., Xie, L. and Baser, O. (2014) Outcomes and Treatment Patterns of Adding a Third Agent to 2 OADs in Patients with Type 2 Diabetes. Journal of Managed Care Pharmacy, 20, 501-512.

https://doi.org/10.18553/jmcp.2014.20.5.501

[18] Gómez-Peralta, F., Carramiñana-Barrera, F., Félix-Redondo, F.J. and Fraile-Gómez, 
J. (2012) Glycaemic Control in Patients with Type 2 Diabetes Switching from Premixed Insulin to Long-Acting Basal Insulin Analogue Plus Oral Antidiabetic Drugs: An Observational Study. International Journal of Clinical Practice, 66, 959-968. https://doi.org/10.1111/j.1742-1241.2012.03000.x

[19] Plat, A., Penning-van Beest, F., Kessabi, S., Groot, M. and Herings, R. (2009) Change of Initial Oral Antidiabetic Therapy in Type 2 Diabetic Patients. Pharmacy World \& Science, 31, Article No. 622. https://doi.org/10.1007/s11096-009-9321-0

[20] Asche, C.V., McAdam-Marx, C., Shane-McWhorter, L., Sheng, X. and Plauschinat, C.A. (2008) Association between Oral Antidiabetic Use, Adverse Events and Outcomes in Patients with Type 2 Diabetes. Diabetes, Obesity and Metabolism, 10, 638645. https://doi.org/10.1111/j.1463-1326.2007.00758.x 